\title{
Quantification of EGFR mutations in primary and metastatic tumors in non-small cell lung cancer
}

\author{
Bing Wei, Ke Yang, Jiuzhou Zhao, Yuxi Chang, Zihui Ma, Bing Dong, Yongjun Guo and Jie Ma*
}

\begin{abstract}
Background: EGFR mutation detection has been widely applied in the prediction of TKIs therapy in Non-Small Cell Lung Cancer (NSCLC). Metastatic tumors rather than primary tumors were usually assayed for those patients in advanced stages. Although the difference of EGFR mutation status in primary and metastatic tumors has been reported, the quantitative difference (ratio of mutated EGFR among total EGFR) in primary and metastatic tumors as well as in different sites of primary tumors was not clear.

Methods: Genomic DNA in Formalin Fixed-Paraffin Embedded samples of primary and metastatic tumors of 50 NSCLC patients was extracted. Real-time fluorescent PCR was performed to quantify the EGFR mutation ratios.

Results: The EGFR mutation ratios detected in different sites of primary tumors were highly concordant, whereas the EGFR mutation ratios in metastatic tumors were lower than those in primary tumors.

Conclusions: Randomly chosen sample may reliably represent the type and ratio of mutations of EGFR in primary tumors. EGFR mutation ratios in primary tumors and metastatic tumors are different. If metastatic tumors are used for the detection of EGFR mutation, the sensitivity of the detection assay must be considered.
\end{abstract}

Keywords: Non-small cell lung cancer, EGFR mutations, Primary tumors, Metastatic tumors, Quantification

\section{Background}

Epidermal growth factor receptor (EGFR) is a receptor tyrosine kinase encoded by the c-erb-B1 proto-oncogene. Multiple studies showed that the efficacy of tyrosine kinase inhibitors (TKIs) in the treatment of Non-Small Cell Lung Cancer (NSCLC) is highly correlated with EGFR mutation status in exon 18-21 [1-4].

EGFR mutations have been detected in $30-50 \%$ of NSCLC patients in China $[5,6]$. The detection methods include PCR-sequencing, Taqman real-time PCR, DHPLC, and SARMS [6-12]. For some of the NSCLC patients, especially those with metastatic cancer, the primary tumor specimen may not be available; therefore EGFR mutations in metastases are often analyzed. However, the molecular nature of the tumors may change during metastasis, and currently it is unclear whether the mutations detected in primary tumors correlate with those in metastases. It has been reported that EGFR mutations detected in metastases are 10-60\% inconsistent with those in primary tumors $[13,14]$. It is worth noting that gefitinib has been reported to be beneficial for patients in which EGFR mutations were detected in metastases but not primary tumors [15]. However, since these studies used qualitative detection of EGFR mutations, it is impossible to quantitatively evaluate the abundance of EGFR mutations in the primary tumor and metastases.

Real-time fluorescent PCR detection of mutations is a straightforward method with high sensitivity and reliability. In this study, we used real-time PCR to quantitatively detect EGFR mutations in primary and metastatic tumors. Fifty Chinese NSCLC patients that harbor EGFR mutations in their primary tumors were identified. EGFR mutation status and abundance were compared among different areas of a primary tumor and its corresponding metastatic tumor of the same individual. Our study provides new insights on clinical interpretation of EGFR mutation status in different specimens.

\footnotetext{
* Correspondence: majie@medmail.com.cn

Department of Pathology, Henan Cancer Hospital, the Affiliated Cancer

Hospital of Zhengzhou University, Zhengzhou 450008, Henan, China
} 


\section{Methods}

Patients and Clinical Characteristics

From the patients who visited Henan Cancer Hospital between January 2010 and December 2012, those diagnosed with NSCLC by histological examination were tested for EGFR mutations, and 50 patients that were positive for EGFR mutations in the primary tumor samples were randomly selected for further evaluation. Their clinical and pathological characteristics are listed in Table 1. All study subjects never received TKI treatment before the study, and the formalin-fixed paraffin-embedded (FFPE) specimens were available for both the primary and metastatic tumors. Patients consented to tissue specimen collection prospectively, and the study was approved by the ethics committee of Henan Cancer Hospital, the Affiliated Cancer Hospital of Zhengzhou University.

\section{Clinical specimens}

Pathological diagnosis was established as NSCLC by assessing the $\mathrm{HE}$ stained sections of formalin-fixed paraffin-embedded primary tumors. The tumor contents was $>50 \%$ for slides prepared from primary tumors, and $>20 \%$ for those from lymph node metastases. For each subject, four DNA samples corresponding to the two lateral regions and one center region of the primary tumor specimen, as well as one from lymph node metastases were prepared. For each sample, DNA was isolated from no less than 5 pieces of consecutive $5 \mu \mathrm{m}$

Table 1 Clinical characteristics of $\mathbf{5 0}$ advanced NSCLC cases and the detection of EGFR mutations in primary tumors and metastases

\begin{tabular}{|c|c|c|c|}
\hline & No. cases & $\begin{array}{l}\text { Mutation rates of } \\
\text { primary tumor }(\%)\end{array}$ & $\begin{array}{l}\text { Mutation rates } \\
\text { of metastases (\%) }\end{array}$ \\
\hline \multicolumn{4}{|l|}{$\overline{\text { Age }}$} \\
\hline$>60$ & 38 & 100 & 100 \\
\hline$\leq 60$ & 12 & 100 & 75 \\
\hline \multicolumn{4}{|l|}{ Gender } \\
\hline Male & 11 & 100 & 72.7 \\
\hline Female & 39 & 100 & 100 \\
\hline \multicolumn{4}{|l|}{ Type } \\
\hline Adenocarcinoma & 49 & 100 & 95.9 \\
\hline $\begin{array}{r}\text { Squamous cell } \\
\text { carcinoma }\end{array}$ & 1 & 100 & 0 \\
\hline \multicolumn{4}{|l|}{ Stage } \\
\hline$\| \mathrm{II}$ & 28 & 100 & 89.3 \\
\hline IV & 22 & 100 & 100 \\
\hline \multicolumn{4}{|l|}{ Smoking status } \\
\hline Smoker & 10 & 100 & 80 \\
\hline Non-smoker & 40 & 100 & 97.5 \\
\hline
\end{tabular}

slides of Formalin-fixed paraffin-embedded (FFPE) specimens that had been stored at room temperature for less than 5 years.

\section{Isolation of genomic DNA}

Genomic DNA from the FFPE samples was isolated by using QIAamp DNA FFPE Tissue Kit (Qiagen) according to the manufacturer's instructions. The DNA concentration was measured by UV spectrometer and adjusted to $20 \sim 50 \mathrm{ng} / \mu \mathrm{l}$. DNA samples were stored at $-20^{\circ} \mathrm{C}$ before use.

\section{Quantitative measurement of EGFR mutation ratio}

45 types of EGFR mutations corresponding to hotspots in exons 18, 19, 20 and 21 were detected by using $\mathrm{Hu}$ man EGFR mutation quantitative PCR detection kit (ACCB, Beijing, China) according to the manufacturer's instructions. Real-time PCR were performed on Stratagene Mx3000P PCR machine with the following settings: $95^{\circ} \mathrm{C}$ for $10 \mathrm{~min}$, followed by 40 cycles of $95^{\circ} \mathrm{C}$ for $15 \mathrm{sec}$ and $60^{\circ} \mathrm{C}$ for $1 \mathrm{~min}$. The mutant and wild-type alleles were amplified separately, and the levels of each mutation in the sample were calculated by normalizing to standard curves. The mutation ratio was defined as [mutation ratio $\%=$ level of mutants/(level of mutants + level of wild type allele) $\times 100 \%]$.

\section{Statistical analysis}

Statistical analysis was carried out using SPSS version 16.0 software (SPSS Inc., Chicago, IL, US). Fisher's exact test was used to analyze whether the different categories had different positive rates. Kappa test was used to analyze whether the two sampling regions had consistent outcomes. Wilcoxon matched pairs test was used to compare the mutation ratios from the two regions. Twosided $\mathrm{p}<0.05$ was considered statistically significant.

\section{Results}

EGFR mutations in primary tumors and metastases

Of the 50 cases of NSCLC that had EGFR mutations in primary tumors, exon 19 mutations (in-frame deletions only) were present in 28 cases (56\%), and exon 21 (L858R point mutations only) mutations were detected in 22 cases (44\%). Mutations in exon 19 and 21 were mutually exclusive and no multiple mutations were found. Of the metastases samples, 47 were positive for EGFR mutation (94\% concordance with the detection in primary tumors), and exon 19 and exon 21 mutations were detected in 26 cases (55\%, 93\% concordance) and 21 cases (45\%, 95\% concordance), respectively. Notably, all cases presented the same mutation type in the matching primary and metastatic tumors. EGFR mutation detection and the clinical characteristics were listed in Table 1 . Among the 50 subjects, only 3 (6\%) had different test results for EGFR mutations in 
Table 2 Quantitative measurement of EGFR mutation ratios in 3 primary tumor sites and one metastases of the same patient

\begin{tabular}{|c|c|c|c|c|c|c|}
\hline \multirow[t]{2}{*}{ ID } & \multicolumn{5}{|c|}{ Mutation ratio $(\%)$ in different primary tumor sites } & \multirow{2}{*}{$\begin{array}{l}\text { Mutation } \\
\text { ratio (\%) of } \\
\text { metastases }\end{array}$} \\
\hline & 1 & 2 & 3 & Median & Deviation (\%)* & \\
\hline E001 & 85.9 & 91.1 & 80.1 & 85.9 & 12.8 & $<10$ \\
\hline E002 & 39.1 & 25.9 & 44 & 39.1 & 49.8 & 41 \\
\hline E003 & $<10$ & $<10$ & $<10$ & $<10$ & 0.0 & $<10$ \\
\hline E004 & 82.2 & 76.7 & 66.9 & 76.7 & 20.3 & 13.3 \\
\hline E005 & 43.9 & 40.5 & 45.4 & 43.9 & 11.3 & 41.2 \\
\hline E006 & 35.4 & 42.7 & 39.3 & 39.3 & 18.7 & $<10$ \\
\hline E007 & 70.1 & 71.8 & 66.5 & 70.1 & 7.6 & 72.9 \\
\hline E008 & 79.8 & 85.1 & 88.9 & 85.1 & 10.8 & 28.1 \\
\hline E009 & 66.1 & 64.3 & 49.3 & 64.3 & 28.0 & 45.9 \\
\hline E010 & 54.2 & 83.6 & 77.6 & 77.6 & 40.9 & 15.9 \\
\hline E011 & $<10$ & $<10$ & $<10$ & $<10$ & 0.0 & $<10$ \\
\hline E012 & $<10$ & $<10$ & $<10$ & $<10$ & 0.0 & $<10$ \\
\hline E013 & 44.7 & 27.2 & 49.1 & 44.7 & 54.3 & 22.9 \\
\hline E014 & 55.5 & 64.3 & 66.6 & 64.3 & 17.9 & 31.2 \\
\hline E015 & 18.7 & 23.6 & 13.9 & 18.7 & 51.8 & Negative \\
\hline E016 & 37.6 & 45.2 & 38.2 & 38.2 & 18.8 & $<10$ \\
\hline E017 & 23.8 & 28.9 & 23.9 & 23.9 & 20.0 & 30.4 \\
\hline E018 & 62.3 & 69.6 & 58.2 & 62.3 & 18.0 & 43.8 \\
\hline E019 & $<10$ & $<10$ & $<10$ & $<10$ & 0.0 & $<10$ \\
\hline E020 & $<10$ & $<10$ & $<10$ & $<10$ & 0.0 & $<10$ \\
\hline E021 & 48.6 & 47 & 40.2 & 47 & 18.6 & 25.3 \\
\hline E022 & 28.6 & 35.1 & 34.9 & 34.9 & 19.8 & 20.9 \\
\hline E023 & 38.9 & 31.7 & 30.9 & 31.7 & 23.6 & 35.9 \\
\hline E024 & $<10$ & $<10$ & $<10$ & $<10$ & 0.0 & $<10$ \\
\hline E025 & 44.9 & 38.4 & 45.1 & 44.9 & 15.7 & $<10$ \\
\hline E026 & 78.9 & 75.2 & 79.2 & 78.9 & 5.1 & 54.9 \\
\hline E027 & $<10$ & $<10$ & $<10$ & $<10$ & 0.0 & Negative \\
\hline E028 & 67.3 & 54.7 & 55.3 & 55.3 & 21.3 & 52.1 \\
\hline E029 & 56.3 & 45.4 & 47.5 & 47.5 & 21.9 & $<10$ \\
\hline E030 & 24.8 & 29.1 & 32.7 & 29.1 & 27.4 & 15.9 \\
\hline E031 & 59.7 & 48.1 & 55.3 & 55.3 & 21.3 & 42.8 \\
\hline E032 & 31.8 & 34.9 & 41.1 & 34.9 & 25.9 & 25.8 \\
\hline E033 & $<10$ & $<10$ & $<10$ & $<10$ & 0.0 & $<10$ \\
\hline E034 & 33.8 & 30.1 & 27.7 & 30.1 & 20.0 & 28.9 \\
\hline E035 & 42.2 & 38.1 & 45.1 & 42.2 & 16.7 & 40.2 \\
\hline E036 & $<10$ & $<10$ & $<10$ & $<10$ & 0.0 & Negative \\
\hline E037 & 54.7 & 48.4 & 47.1 & 48.4 & 15.2 & $<10$ \\
\hline E038 & 18.3 & 28.7 & 22.2 & 22.2 & 45.1 & 14.9 \\
\hline E039 & 40.2 & 41.8 & 30.2 & 40.2 & 31.0 & 28.9 \\
\hline E040 & 38.4 & 45.2 & 43.2 & 43.2 & 16.1 & $<10$ \\
\hline E041 & 58.3 & 51.9 & 48.3 & 51.9 & 18.9 & 45.5 \\
\hline E042 & 45.3 & 40.2 & 42.6 & 42.6 & 11.9 & 45.9 \\
\hline
\end{tabular}


Table 2 Quantitative measurement of EGFR mutation ratios in 3 primary tumor sites and one metastases of the same patient (Continued)

\begin{tabular}{lllllll}
\hline E043 & $<10$ & $<10$ & $<10$ & $<10$ & 0.0 & $<10$ \\
E044 & 51.1 & 55.3 & 44.8 & 51.1 & 20.8 & 12.5 \\
E045 & 65.7 & 62.9 & 71.2 & 65.7 & 13.7 & 49.8 \\
E046 & 28.9 & 29.8 & 33.1 & 29.8 & 12.7 & 19.6 \\
E047 & 43.8 & 45.9 & 49.7 & 45.9 & 24.8 & 43.1 \\
E048 & 67.3 & 63.2 & 52.2 & 63.2 & 34.5 & 33.8 \\
E049 & 39.1 & 43.9 & 30.8 & 21.8 & 30.3 & 27.8 \\
E050 & 28.9 & 21.8 & 21.6 & 22.5 \\
\hline
\end{tabular}

*Mutation deviation (\%) of primary tumors was defined as (Emax-Emin)/Emd $\times 100 \%$, where Emax, Emin, and Emd are the maximum, minimum and median value of EGFR mutation ratios at different primary tumor sites. If all three mutation ratios in primary sites were below $10 \%$, the deviation was calculated as $0 \%$.

primary tumor and metastases, however, the difference was insignificant $(P=0.242)$ as analyzed by Fisher's exact test.

\section{EGFR mutations at different sites of primary tumors of} the same patient

We performed quantitative measurement of EGFR mutations at different sites of primary tumors (Table 2). The median mutation deviation for different primary sites (see footnote of Table 2 for the formula of calculation) was $18.3 \%$ (with a range of $0.0 \% \sim 54.3 \%$ ), indicating that the results of the quantitative measurement of EGFR mutations in different sites of primary tumor in the same patient have a high level of concordance.

Quantitative measurement of EGFR mutations in primary tumors and metastases of the same patient

Although the qualitative measurement of EGFR mutations in primary sites and metastases showed a high level of concordance (94\%), the quantitative measurements had significant difference (Tables 2 and 3). The Kappa value of the two groups was $0.615(\mathrm{P}<0.01)$, indicating that different sampling sites only had moderate concordance. Overall, the mutation ratios of metastases is significantly lower than those of primary tumors $(\mathrm{P}<0.01)$ as analyzed by Wilcoxon matched pairs test.

\section{Discussion}

NSCLC patients carrying EGFR mutations often benefit from TKI treatments with reduced sizes of primary

Table 3 EGFR mutation ratios in primary tumor and metastases of the same patients

\begin{tabular}{|c|c|c|c|}
\hline \multicolumn{2}{|c|}{ EGFR mutation ratio } & \multirow[t]{2}{*}{ No. cases } & \multirow[t]{2}{*}{$\%$} \\
\hline Primary & Metastases & & \\
\hline$>10 \%$ & $>10 \%$ & 32 & $\overline{64 \%}$ \\
\hline$<10 \%$ & $<10 \%$ or negative & 10 & $20 \%$ \\
\hline$>10 \%$ & $<10 \%$ or negative & 8 & $16 \%$ \\
\hline$<10 \%$ & $>10 \%$ & 0 & 0 \\
\hline
\end{tabular}

tumors and metastases visualized by medical imaging. For a subset of patients, however, TKIs treatment only diminished the primary tumors but had no effect on metastases, and occasionally the metastases even became enlarged or more numerous over time. It raises the questions whether the abundance of EGFR mutations are different in different primary tumor sites, and whether the abundance and type of mutations are the same for primary tumors and metastases. Our study revealed the following characteristics of EGFR mutations.

First of all, although the mutation ratio in different primary tumor sites varied (the median value ranged from $<10 \%$ to $85.9 \%$ ) (Table 2 ), the deviation of the mutation ratio in different primary sites was limited (median was $18.3 \%$ with a range of $0.0 \% \sim 54.3 \%$ ) (Table 2 ), indicating that different sites of primary tumor in the same patient have a high level of concordance. During the routine pathological evaluation of FFPE specimens of primary tumors, EGFR mutations were often tested only in one randomly chosen sample. Our study showed that when the area of cancerous cells were greater than $50 \%$, a randomly chosen sample may reliably represent the type and ratio of mutations of EGFR in primary tumors.

Secondly, when the EGFR mutations were present in primary tumors, they could be detected in metastases with a high concordance regardless of the mutation ratios. The concordance of EGFR mutations in primary tumor and metastases is $94 \%$, and that for mutation ratios is $84 \%$. Moreover, different types of mutations, such as those in exon 19 and 21, were also identified with high concordances (93\% and 95\%, respectively), suggesting that the type of mutation did not affect the detection rates.

In addition, mutation detection is also affected by the proportion of cancerous cells in a sample. Therefore, for metastases with a lower number of cancerous cells, highly sensitive methods such as real-time PCR are highly recommended.

Moreover, in comparison to those in primary tumor sites, the mutation ratios in metastases were reduced and 
occasionally undetectable (16\% samples had reduced or negative detection). These results suggest that the use of metastases specimens might generate false negative diagnosis for EGFR mutations that could have been present in primary tumors. The decreased EGFR mutation ratios in metastases suggest that EGFR mutations may not be essential for metastasis, which may underlie the lack of response to TKIs in metastases despite an positive outcome for the primary tumors. Notably, in this study we had one case of squamous cell carcinoma that harbors EGFR exon 19 mutation in the primary tumor, but the mutation was undetectable in metastases. It is unclear if it is due to the nature of squamous cell carcinoma.

In addition to the different pathological nature of primary tumor and metastases, the inconsistency in the identification of EGFR mutation may also be due to the sensitivity of the detection methods. For instance, Sanger sequencing may give a negative calling for samples with a mutation ratio of $<10 \%$, and therefore leads to low concordance for EGFR mutations in different samples of the same patients. Our study showed that by using quantitative real-time PCR, the positive identification of mutations in primary tumor and metastases had a $94 \%$ concordance, and for the quantitative measurement of mutation ratio the concordance was $84 \%$. Hence, metastases specimens could be used for mutation assessment if the specimen for primary tumors is lacking, but the detection methods must be of high sensitivity. Recently, the abundance of mutations of predictive biomarkers, such as EGFR and KRAS, has drawn more attention [16-18]. It has been shown that the abundance of EGFR mutations predicts benefit from EGFR-TKI treatment for NSCLC [16]. Similarly, colorectal cancer patients with low abundance of KRAS mutation have been reported to benefit from EGFR antibody therapy [17]. Precise quantification of EGFR mutation abundance may become a trend in clinic to help with a better patient selection and better treatment strategies. To enable precise quantification of mutation ratio, real time PCR with a standard curve such as the method applied in this report serves as one of the optimal options.

In this study, only subjects with EGFR mutations in primary tumors were included, but it did not address the issues of positive mutation detection in metastases but negative in primary sites. Future studies should combine the prognosis data of the patients that received TKIs therapy and analyze the correlation between the quantitative measurement of EGFR mutations in primary and metastatic tumors and their response to TKIs, especially those with inconsistent measurement of EGFR mutation status in those sites. These studies could provide guidance for doctors to make informed decision in NSCLC treatment.

\section{Conclusions}

Randomly chosen sample may reliably represent the type and ratio of EGFR mutations in primary tumors. EGFR mutation ratios in primary and metastatic tumors are different. If metastatic tumors are used for EGFR mutation detection, the sensitivity of the detection assay must be taken into consideration.

\section{Competing interests}

The authors declare that they have no competing interests.

\section{Authors' contributions}

BW, KY and JZ carried out the DNA isolation. BW, YC, ZM, BD and YG performed real time PCR for quantification of EGFR mutation. BW and JM performed the statistical analysis. BW and JM designed the study and drafted the manuscript. All authors read and approved the final manuscript.

\section{Acknowledgement}

This work was supported by a Research Plan of Medical Science and Technology Project of Henan Province (No. 201204105) (to JM).

Received: 18 November 2013 Accepted: 3 January 2014

Published: 8 January 2014

\section{References}

1. Paez JG, Janne PA, Lee JC, Tracy S, Greulich H, Gabriel S, Herman P, Kaye FJ, Lindeman N, Boggon TJ, et al: EGFR mutations in lung cancer: correlation with clinical response to gefitinib therapy. Science (New York, NY) 2004, 304:1497-1500.

2. Lynch TJ, Bell DW, Sordella R, Gurubhagavatula S, Okimoto RA, Brannigan BW, Harris PL, Haserlat SM, Supko JG, Haluska FG, et al: Activating mutations in the epidermal growth factor receptor underlying responsiveness of non-smallcell lung cancer to gefitinib. N Engl J Med 2004, 350:2129-2139.

3. Mok TS, Wu YL, Thongprasert S, Yang CH, Chu DT, Saijo N, Sunpaweravong $P$, Han B, Margono B, Ichinose $Y$, et al: Gefitinib or carboplatin-paclitaxel in pulmonary adenocarcinoma. N Engl J Med 2009, 361:947-957.

4. Kobayashi S, Boggon TJ, Dayaram T, Janne PA, Kocher O, Meyerson M, Johnson BE, Eck MJ, Tenen DG, Halmos B: EGFR mutation and resistance of non-small-cell lung cancer to gefitinib. N Engl J Med 2005, 352:786-792.

5. Song G, Di L, Ren J, Zhang L, Yu J: Analysis of EGFR mutation in Chinese non-small cell lung cancer patients. J Mod Oncol 2008, 16:553-556.

6. Feng Q, Li X, Chen Z, He J, Wang C, Zhou L, Xue W: Epidermal growth factor receptor gene mutations and clinicopathologic correlation in 309 patients with non-small cell lung cancer. Chin J Pathol 2011, 40:660-663.

7. Abo-Elwafa HA, Attia FM, Sharaf AE: The prognostic value of p53 mutation in pediatric marrow hypoplasia. Diagn Pathol 2011, 6:58.

8. Carbonell P, Turpin MC, Torres-Moreno D, Molina-Martinez I, Garcia-Solano J, Perez-Guillermo M, Conesa-Zamora P: Comparison of allelic discrimination by $\mathrm{dHPLC}, \mathrm{HRM}$, and TaqMan in the detection of BRAF mutation V600E. J Mol Diagn 2011, 13:467-473.

9. Didelot A, Le Corre D, Luscan A, Cazes A, Pallier K, Emile JF, Laurent-Puig P, Blons H: Competitive allele specific TaqMan PCR for KRAS, BRAF and EGFR mutation detection in clinical formalin fixed paraffin embedded samples. Exp Mol Pathol 2012, 92:275-280.

10. Endo K, Konishi A, Sasaki H, Takada M, Tanaka H, Okumura M, Kawahara M, Sugiura H, Kuwabara Y, Fukai l, et al: Epidermal growth factor receptor gene mutation in non-small cell lung cancer using highly sensitive and fast TaqMan PCR assay. Lung Cancer 2005, 50:375-384.

11. Hamfjord J, Stangeland AM, Skrede ML, Tveit KM, Ikdahl T, Kure EH: Wobble-enhanced ARMS method for detection of KRAS and BRAF mutations. Diagn Mol Pathol 2011, 20:158-165.

12. Liu Y, Liu B, Li XY, Li JJ, Qin HF, Tang CH, Guo WF, Hu HX, Li S, Chen CJ, et al: A comparison of ARMS and direct sequencing for EGFR mutation analysis and tyrosine kinase Inhibitors treatment prediction in body fluid samples of nonsmall-cell lung cancer patients. J Exp Clin Cancer Res 2011, 30:111.

13. Sun L, Zhang Q, Luan H, Zhan Z, Wang C, Sun B: Comparison of KRAS and EGFR gene status between primary non-small cell lung cancer and local lymph node metastases: implications for clinical practice. J Exp Clin Cancer Res 2011, 30:30 
14. Monaco SE, Nikiforova MN, Cieply K, Teot LA, Khalbuss WE, Dacic S: A comparison of EGFR and KRAS status in primary lung carcinoma and matched metastases. Hum Pathol 2010, 41:94-102.

15. Sun L, Zhang Q, Li H, Zhan Z, Sun B: Comparison of KRAS and EGFR gene statuses between primary non-small cell lung cancer and local lymph node metastases and their clinical significance. Chin J Clin Oncol 2012 39:970-973.

16. Zhou Q, Zhang XC, Chen ZH, Yin XL, Yang JJ, Xu CR, Yan HH, Chen HJ, Su J, Zhong WZ, et al: Relative abundance of EGFR mutations predicts benefit from gefitinib treatment for advanced non-small-cell lung cancer. J Clin Oncol 2011, 29:3316-3321.

17. Yu S, Xiao X, Lu J, Qian X, Liu B, Feng J: Colorectal cancer patients with low abundance of KRAS mutation may benefit from EGFR antibody therapy. PloS One 2013, 8:e68022.

18. Wu YC, Chang IC, Wang CL, Chen TD, Chen YT, Liu HP, Chu Y, Chiu YT, Wu TH, Chou LH, et al: Comparison of IHC, FISH and RT-PCR methods for detection of ALK rearrangements in 312 non-small cell lung cancer patients in Taiwan. PloS One 2013, 8:e70839.

doi:10.1186/1756-9966-33-5

Cite this article as: Wei et al:: Quantification of EGFR mutations in

primary and metastatic tumors in non-small cell lung cancer. Journal of Experimental \& Clinical Cancer Research 2014 33:5.

\section{Submit your next manuscript to BioMed Central and take full advantage of:}

- Convenient online submission

- Thorough peer review

- No space constraints or color figure charges

- Immediate publication on acceptance

- Inclusion in PubMed, CAS, Scopus and Google Scholar

- Research which is freely available for redistribution 